(RESEARCH ARTICLE)

\title{
Formulation and characterization of papaya leaf gel
}

\author{
Das Tama, Manna Mahuli and Rudra Anandamoy* \\ Bengal School of Technology, Sugandha, Delhi Road, Hooghly-712102, West Bengal, India.
}

Publication history: Received on 29 February 2020; revised on 06 March 2020; accepted on 09 March 2020

Article DOI: https://doi.org/10.30574/gscbps.2020.10.3.0054

\begin{abstract}
The study was designed for ethanolic extraction of papaya leaf, phytochemical screening of the extract, formulation of papaya leaf gel by using carbopol 934 and characterization of the herbal gel. The fresh papaya leaves were collected and extracted by maceration process using ethanol as a solvent. The extract was analysed by UV spectrophotometer and IR spectroscopy for identification of phytochemical compounds. Then the phytochemical evaluation was performed and the presence of glycoside, tannins, flavonoids and saponins were observed. The herbal gel was prepared by using carbopol 934 polymer and isopropyl alcohol as penetration enhancer. $\mathrm{pH}$ of 6 was observed by using the pH meter. Swelling index of blank gel was $190 \%$ and the swelling index of herbal gel was $220 \%$. In the spreadability study, the diameter of the spot was observed within 3.5-3.7 cm. The interaction study between phytochemicals and the excipients was carried out by FTIR spectroscopy.
\end{abstract}

Keywords: Papaya leaf gel; Carbopol 934; Ethanolic extraction; Dermal preparation

\section{Introduction}

Topical delivery is an attractive route for local and systemic dermatological deseases. It enchances absorption due to its deeper penetration to the skin. It is less toxic and more effective that reduces systemic effect. Gels are basically used as delivery systems for topical administered drug directly to the skin, eye or mucous membrane [1]. Topical delivery is defined as the application of a formulation containing drug to the skin to directly treat cutaneous disorders (eg. acne) with the intent of containing pharmacological or other effect of the drug to the surface of the skin or within [2,3,4]. Within the major group of semisolid preparations, the use of transparent gels has explained both in cosmetic and pharmaceutical preparations. In spite of many advantages of gel, a major limitation is in the delivery of hydrophobic drugs [5,6]. Gel are constituted by entrapment of large amounts of aqueous or hydroalcoholic liquid in a network of colloidal solid particles, which may be organic or inorganic polymers of natural or synthetic origin. The higher aqueous component permits greater dissolution of drugs, and permits easy migration of the drug as compared to the ointment or cream base. However, this makes gels poor vehicle for hydrophobic drugs. This limitation of gels can be overcome by making emulgel [7]. A tropical plant, Carica papaya, a flowering plant, having five yellow orange or cream white petals. The fruits have many seeds surrounding by a smooth yellow to orange red flash. They are mainly trees or shrubs comprising about 35 species of six genera. The young leaves Carica papaya contain carpine which is an alkaloid. Several minerals are reported in leaves of Carica papaya like calcium, magnesium, sodium, iron and some vitamins are ascorbic acid, thiamine and riboflavin. The latex is rich in chymopapain and papain. The Carica papaya leaf extract was investigated for its anti-inflammatory activity, anti-fungal activity and wound healing activity [8].

\footnotetext{
* Corresponding author: Rudra Anandamoy Phone (Mob): +91-8697851515
} 


\section{Preparation of plant extract}

At first the fresh papaya leaves were collected. Then the leaves were washed properly with water. After that the leaves were shade dried and then grinded into small particles by mechanical grinder. Then the powder was extracted by cold maceration process with help of ethanol. In this process the fine powder was placed into ethanol for 7-8 days. After that the extract was filtered by whatman filter paper and the filtrate was collected. Then the solvent was evaporated by rotary evaporator under reduced pressure [9].

\section{Phytochemical evaluation of plant extract}

\subsection{Qualitative test for alkaloid}

$1 \mathrm{ml}$ of $1 \% \mathrm{HCl}$ was added to $3 \mathrm{ml}$ of each extract in different test-tube. Each mixture was heated for $2 \mathrm{~min}$ in a water bath while stirring continuously. It was cooled and filtered. $1 \mathrm{ml}$ of filtrate from above was added to $0.5 \mathrm{ml}$ of Mayer's reagent. $1 \mathrm{ml}$ of each filtrate from above was added to $0.5 \mathrm{ml}$ of Wagner's reagent in different test tube.

\subsection{Qualitative test for tannin}

Ferric chloride $\left(\mathrm{Fecl}_{3}\right)$ Test: $5 \mathrm{~g}$ of ferric chloride was dissolved and made up to $100 \mathrm{ml}$ with distilled water. $0.5 \mathrm{ml}$ of $\mathrm{FeCl}_{3}$ was then added to $2 \mathrm{ml}$ of the extract.

$\mathrm{KOH}$ Test: $1 \mathrm{ml}$ of freshly prepared $10 \% \mathrm{KOH}$ was added to $1 \mathrm{ml}$ of each extract in difference test tube.

\subsection{Qualitative test for flavonoid}

Two drops of $\mathrm{NaOH}$ solution was added to $1 \mathrm{ml}$ of each extract in difference test tubes. Two drops of $\mathrm{AlCl}_{3} \mathrm{Solution}$ was added to above, followed by addition of concentrated $\mathrm{H}_{2} \mathrm{SO}_{4}$.

\subsection{Qualitative test for saponin}

$2 \mathrm{ml}$ of each of the Fehling solution A and B was added to $3 \mathrm{ml}$ of the extract. The mixture was boiled for $5 \mathrm{~min}$.

\subsection{Qualitative test for glycoside}

$5 \mathrm{ml}$ of distilled water was added to $2 \mathrm{ml}$ of the papaya leaf extract. $2 \mathrm{ml}$ of the $\mathrm{H}_{2} \mathrm{SO}_{4}$ was also added the mixture and was boiled in water bath for $15 \mathrm{~min}$ and allowed to cool. The mixture was neutralized with $20 \% \mathrm{KOH}$ solution. $1 \mathrm{ml}$ of equal parts of Fehling solution A and B (each) was added to the mixture and boiled for 15 min in a water bath [10].

\subsection{Thin layer chromatography (TLC) of papaya leaf extract}

Silica gel G was used as stationary phase and ethyl acetate and hexane were used as mobile phase. The sample was spotted by capillary tube. After completion of run the spots were identified by UV chamber. The distance travelled by solutes and mobile phase was measured. Then $\mathrm{R}_{\mathrm{f}}$ value was calculated.

\subsection{Analysis of extract by UV visible spectrophotometer}

The ethanolic extract was diluted by double distilled (DD) water. Then the sample was analysed by UV visible spectrophotometer within the range of 200-800 $\mathrm{nm}$.

\section{Preparation of papaya leaf gel}

At first the polymer was placed in water for 2 hours. Then the solvent which contains the plant extract was added to the polymer and mixed for twenty minutes. Then the dispersion was allowed to hydrate and swell for sixty minutes. Finally the $\mathrm{pH}$ was adjusted with $98 \%$ triethanolamine with gentle stir. After that the mixture was allowed to equilibrate for twenty four hours [11]. 


\section{Characterization of papaya leaf gel}

\subsection{Determination of $\mathbf{p H}$}

The $\mathrm{pH}$ of the gels was measured using a digital $\mathrm{pH}$ meter. The results were the mean of triplicate readings.

\subsection{Determination of swelling index}

$1 \mathrm{~g}$ of gel formulations was taken on porous aluminium foil and then placed in the petridis containing $10 \mathrm{ml}$ distilled water. The samples were taken from the petridis at a different time interval and left undisturbed in a dry place for some time so that the external liquid was removed and weighed. Swelling index was calculated by the formula as following [12]

$$
\text { Swelling Index }(\mathrm{SW}) \%=\left[\left(\mathrm{W}_{\mathrm{t}}-\mathrm{W}_{0}\right) / \mathrm{W}_{0}\right] \times 100
$$

Where (SW) \% = Equilibrium percent swelling, $\mathrm{W}_{\mathrm{t}}=$ Weight of swollen gel after time $\mathrm{t}, \mathrm{W}_{0}=$ Initial weight of gel at zero time.

\subsection{Determination of spreadability}

For determination of spreadability, $1 \mathrm{~g}$ of gel formulations was placed within the circle of $1 \mathrm{~cm}$ diameter pre-marked on a glass plate of $20 \times 20 \mathrm{~cm}$, on which a second glass plate was placed. A $500 \mathrm{~g}$ weight was allowed to rest on the upper glass plate for $5 \mathrm{~min}$. The diameter due to gel spreading was noted [12].

\subsection{Drug excipients interaction study}

The pure carbopol 934, papaya leaf extract and papaya leaf gel were mixed separately with IR grade KBr and corresponding pellets were prepared by applying specified pressure in a hydraulic press. The pellets were scanned over a wave number range of 4000 to $400 \mathrm{~cm}^{-1}$ in FTIR spectroscope.

\section{Results and discussion}

The UV-visible spectrum of ethanolic extract of C. papayawas taken at the wavelength of 200-800 nm. The spectra showed the peaks at $675 \mathrm{~nm}, 428.5 \mathrm{~nm}, 305.5 \mathrm{~nm}$ and $241 \mathrm{~nm}$ with the absorption of $0.486,0.717,0.831$, and 0.961 respectively. There was a peak at $241 \mathrm{~nm}$, which indicates presence of saturated compounds with hetero atoms like $\mathrm{S}$, $\mathrm{O}, \mathrm{N}$ or halogens. Generally the peaks due to this transition occurs from $180 \mathrm{~nm}-250 \mathrm{~nm}$. There was a peak at $305.5 \mathrm{~nm}$, which indicates the presence of aldehydes or ketones containing $\mathrm{S}, \mathrm{O}, \mathrm{N}$ or halogen. The peak at $675 \mathrm{~nm}$ was due to the presence of chlorophyll.

In IR spectrum of carbopol 934 many peaks were observed. The peak observed at $1707 \mathrm{~cm}^{-1}$ which was associated with ketone or aldehyde $\mathrm{C}=0$ stretching. Another peak was observed at $1527 \mathrm{~cm}^{-1}$ which was associated with $\mathrm{C}=\mathrm{C}$ stretching. The other peak was observed at $1452 \mathrm{~cm}^{-1}$ which was associated with $\mathrm{CH}_{2}$ bending and $\mathrm{CH}_{3}$ bending. Here two peaks at $1180 \mathrm{~cm}^{-1}$ and $1048 \mathrm{~cm}^{-1}$ were observed due to the C-O-C stretching and C-OH stretching. Two peaks at $2865 \mathrm{~cm}^{-1}$ and $2984 \mathrm{~cm}^{-1}$ were observed which was associated with alkane C-H stretching. The peak at $1242 \mathrm{~cm}^{-1}$ which was associated with alcohol C-O stretching (Figure 1).

IR spectrum of ethanolic papaya leaf extract consist several peaks. Two peaks were present at $2846 \mathrm{~cm}^{-1}$ and $2948 \mathrm{~cm}^{-}$ 1 due to the alkane C-H stretching. Two peaks at $1449 \mathrm{~cm}^{-1}$ and $1485 \mathrm{~cm}^{-1}$ were observed which was associated with aromatic $\mathrm{C}=\mathrm{C}$ stretching. The peak at $1243 \mathrm{~cm}^{-1}$ was due to the alcohol C-O stretching and C-N vibrations. Three peaks at $1165 \mathrm{~cm}^{-1}, 1084 \mathrm{~cm}^{-1}$ and $1020 \mathrm{~cm}^{-1}$ were recorded which were associated with alcohol $0-\mathrm{H}$ bending. A peak at 1380 $\mathrm{cm}^{-1}$ was observed which was associated with phenols C-O stretching. Four peaks at $1506 \mathrm{~cm}^{-1}, 1558 \mathrm{~cm}^{-1}, 1550 \mathrm{~cm}^{-1}$ and $1541 \mathrm{~cm}^{-1}$ were observed due to the phenol N-H bending. Two peaks were present at $1417 \mathrm{~cm}^{-1} \mathrm{and}_{1380 \mathrm{~cm}^{-1}}$ which were associated with phenols C-O stretching. A single peak was observed at $1713 \mathrm{~cm}^{-1}$ due to acid C=0 stretching. A peak was present at $2334 \mathrm{~cm}^{-1}$ which was associated with $\mathrm{C} \equiv \mathrm{N}$ stretching. A single peak was recorded at $1380 \mathrm{~cm}^{-1}$ which was associated with alkane $\mathrm{C}-\mathrm{H}$ bending (Figure 2). 


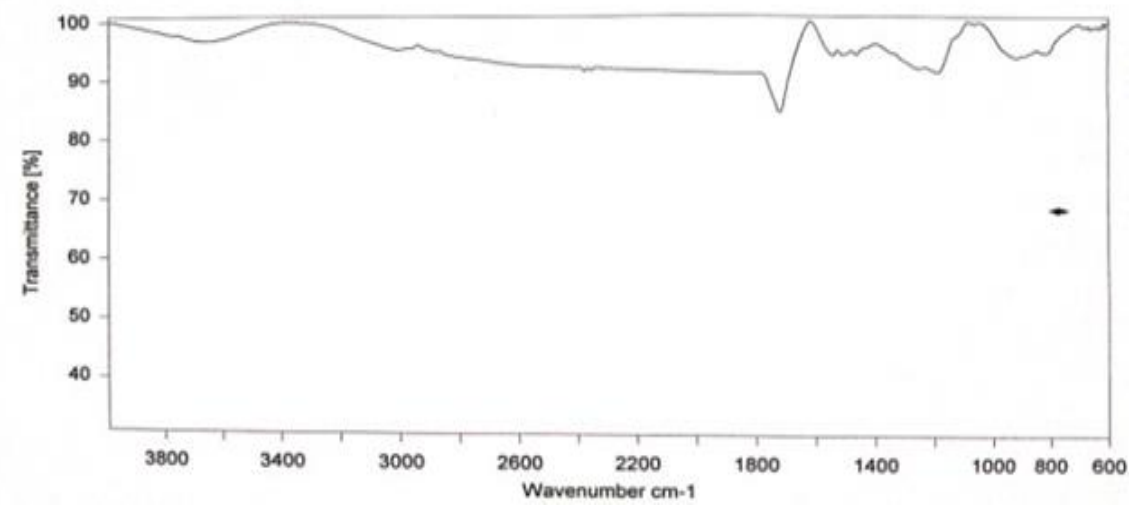

Figure 1 FTIR spectra of carbopol 934

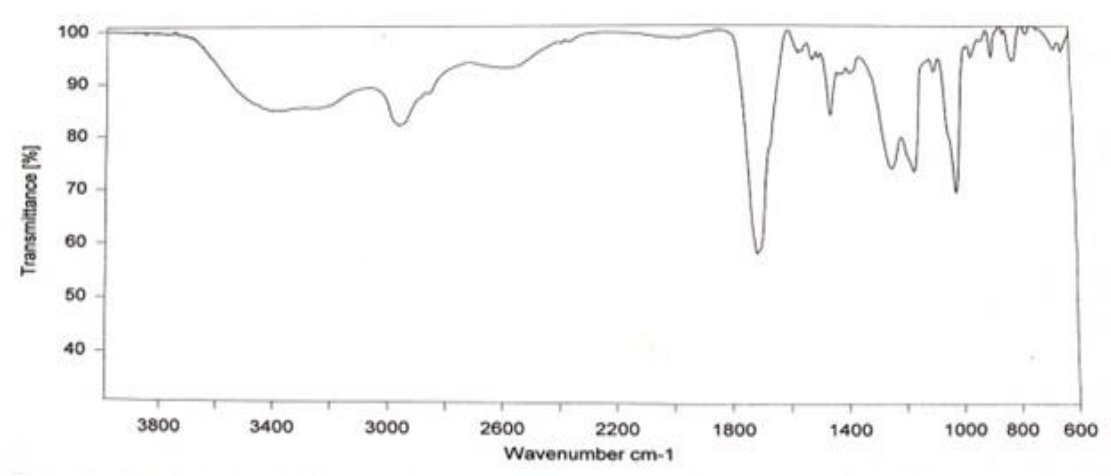

Figure 2 FTIR spectra papaya leaf extract

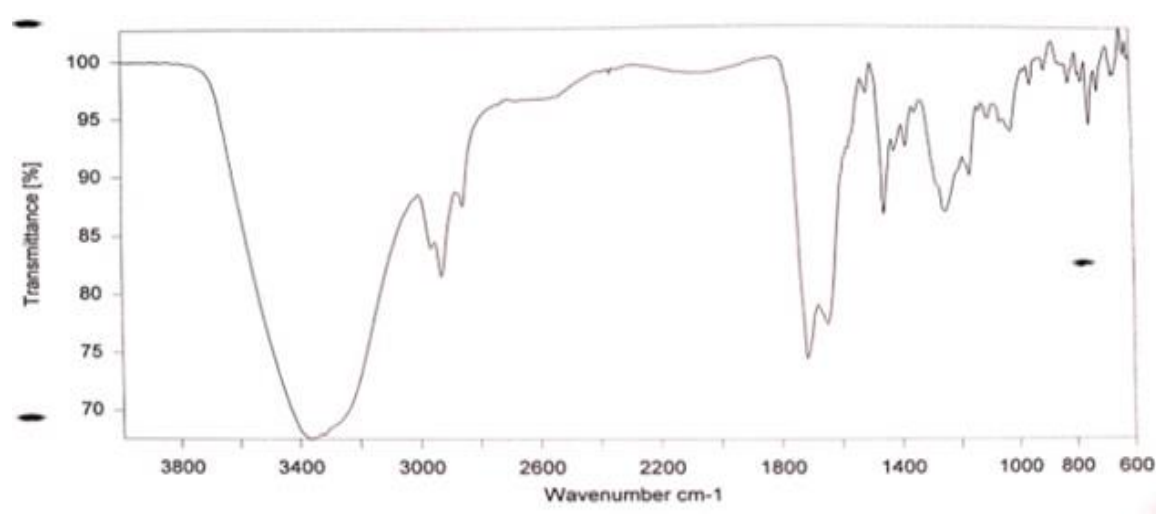

Figure 3 FTIR spectra of papaya leaf gel

In IR spectrum of papaya leaf gel contain many peaks. A single peak at $3367 \mathrm{~cm}^{-1}$ was observed which was associated with alcohol and water $\mathrm{O}-\mathrm{H}$ stretching. Two peaks were recorded at $2925 \mathrm{~cm}^{-1}$ and $2853 \mathrm{~cm}^{-1}$ due to the alkane C-H stretching. A single peak was observed at $1712 \mathrm{~cm}^{-1}$ for acid C=0 stretching. The peak was observed at $1643 \mathrm{~cm}^{-1}$ which was associated with alkene $\mathrm{C}=\mathrm{C}$ stretching. Two peaks at $1451 \mathrm{~cm}^{-1}$ and $1415 \mathrm{~cm}^{-1}$ were recorded for aromatic $\mathrm{C}=\mathrm{C}$ stretching. A couple of peaks were observed at $1376 \mathrm{~cm}^{-1}$ and $1344 \mathrm{~cm}^{-1}$ which were associated with phenols C-O stretching. Another peak was observed at $1245 \mathrm{~cm}^{-1}$ due to the alcohol C-0 stretching. Four peaks were observed at $1162 \mathrm{~cm}^{-1}, 1097 \mathrm{~cm}^{-1}, 1054 \mathrm{~cm}^{-1}$ and $1019 \mathrm{~cm}^{-1}$ which were associated with alcohol O-H bending. The peak at $1505 \mathrm{~cm}^{-}$ ${ }^{1}$ was recorded due to the $\mathrm{N}-\mathrm{H}$ bending. Here some peaks were observed at $897 \mathrm{~cm}^{-1}, 813 \mathrm{~cm}^{-1}, 770 \mathrm{~cm}^{-1}, 714 \mathrm{~cm}^{-1}$ and $779 \mathrm{~cm}^{-1}$ which were associated with aromatic C-H bending (Figure 3). Hence, there was no major interactions between ethanolic extract and excipients except some minor physical interaction which might be due to hydrogen bonding and/or Vander wall forces and/or co-valent bonding. 
Das et al. / GSC Biological and Pharmaceutical Sciences, 2020, 10(03), 089-094

Table 1 Phtochemical evaluation of plant extract

\begin{tabular}{|c|c|c|c|c|}
\hline Material & Compound & Reagent & Color change & Observation/Confirmation \\
\hline \multirow[t]{8}{*}{ Leaf extract } & 1) Alkaloid & Mayer & No & - \\
\hline & & Wagner & No & - \\
\hline & 2) Tannin & $\mathrm{Fecl}_{3}$ & Greenish Dirty & + \\
\hline & & $\mathrm{KoH}$ & white PPt & + \\
\hline & 3) Flavonoid & $\begin{array}{l}\text { Alcl } 3 \text { solution \& } \\
\text { Conc. } \mathrm{H}_{2} \mathrm{SO}_{4}\end{array}$ & Deep red & + \\
\hline & 4) Saponin & $\begin{array}{l}\text { Fehling } \\
\text { solution }\end{array}$ & Brick red precipitate & + \\
\hline & 5) Glycoside & $\begin{array}{l}\text { KoH solution \& } \\
\text { conc. } \mathrm{H}_{2} \mathrm{SO}_{4} \text {, }\end{array}$ & Brick red precipitate & + \\
\hline & & $\begin{array}{l}\text { Fehling } \\
\text { solution }\end{array}$ & & \\
\hline
\end{tabular}

$\mathrm{pH}$ of the papaya leaf gel was observed to be 6. Swelling index of blank gel was $190 \%$ and the swelling index of herbal gel was $220 \%$. In the spreadability study, the diameter of the spot was observed within $3.5-3.7 \mathrm{~cm}$. Rf values were 0.58 and 0.68 which indicate that two components were separated and visualised on TLC chromatogram.

\section{Conclusion}

The study was regarding formulation and characterisation of papaya leaf gel. The papaya leaf gel was prepared by using carbopol 934 and the characterisation of the herbal gel was carried out. Further studies are required for future aspect.

\section{Compliance with ethical standards}

\section{Acknowledgments}

The research work was supported by institutional research fund, Bengal School of Technology, Sugandha, Hooghly, West Bengal, India 712102.

\section{Disclosure of conflict of interest}

Researchers are in a supervisory relationship under corresponding author. The authors report no other conflicts.

\section{References}

[1] Sherwood L.(2007). Human Physiology, 6th Edition. From cells to systems, Thomson Brooks, Stamford.

[2] Noble WC. (1993).The skin microflora and microbial skin disease.University of Cambridge, Cambridge.

[3] Mackie RM. (2002). Clinical dermatology, 5th Edition. Oxford University Press, Oxford.

[4] El Maghraby GM, Barry BW and Williams AC. (2008). Liposomes and skin: From drug delivery to model membranes. European Journal of Pharmaceutical Sciences, 34, 203-222.

[5] Nino M, Calabro G andSantoianni P. (2010). Topical delivery of active principles: The field of dermatological research. Dermatology online Journal, 16(4). 
[6] Kaur LP and Guleri TK. (2013).Topical Gel: A Recent Approach for Novel Drug delivery. Asian Journal of Biomedical\& Pharmaceutical Science, 3(17), 1-5.

[7] Herbaria plants. (1985). e-Monograph of Caricaceae.

[8] Elgadir MA and Adam A. (2013). An in vitro evaluation of films prepared from gelatin Carica papaya methanolic extract for wound healing. International Journal of Drug Delivery, 5, 233-238.

[9] Alabi OA, Haruna MT, Anokwuru CP, Jegede T, Abia H, Okegbe VU and Babatunde EE. (2012). Comparative studies on antimicrobial properties of extracts of fresh and dried leaves of carica papaya (L) on clinical bacterial and fungalisolates. Advances in Applied Science Research, 3(5), 3107-3114.

[10] IkeyiAdachukwu P, Ogbonna Ann 0 and Eze FU. (2013). Phytochemical analysis of paw-paw (Carica papaya) leaves. International Journal of Life Sciences Biotechnology Pharma Research, 2(3), 347-351.

[11] Patel J, Patel B, Banwait HS, Parmar K and Patel M. (2011). Formulation and evaluation of topical aceclofenac gel using different gelling agent. International Journal of Drug Development \& Research, 3 (1), 156-164.

[12] Sah SK, Badola A and Mukhopadhyay S. (2017). Development and evaluation of tioconazol loaded emulgel. International Journal of Applied Pharmaceutics, 9(5), 83-90.

\section{How to cite this article}

Das T, Manna M and Rudra A. (2020). Formulation and characterization of papaya leaf gel. GSC Biological and Pharmaceutical Sciences, 10(3), 89-94. 